Research paper

\title{
Analysis of relationship of high fat mass and low muscle mass with lipid profile in Brazilians aged 80 years or over
}

\author{
Vanessa Ribeiro dos Santos ${ }^{\mathrm{a}}$, Diego Giulliano Destro Christofaro ${ }^{\mathrm{a}, \mathrm{b}}$, \\ Igor Conterato Gomes ${ }^{c}$, Juliana Viezel ${ }^{\mathrm{a}}$, Ismael Forte Freitas Júnior ${ }^{\mathrm{a}, \mathrm{b}}$, \\ Luís Alberto Gobbo ${ }^{\mathrm{a}, \mathrm{b}, *}$ \\ a Motricity Sciences Program, Institute of Bioscience, Universidade Estadual Paulista, UNESP, Avenida 24 1515, Bela Vista, Rio Claro, São Paulo, Brazil
b Department of Physical Education, Universidade Estadual Paulista, UNESP, Rua Roberto Simonsen 305, Centro Educacional, Presidente Prudente, São Paulo,
Brazil
${ }^{c}$ Department of Physical Education, University Maurício of Nassau, Av. Engenheiro Roberto Freire 1514, Natal 59082-095, Brazil
}

A R T I C L E I N F O

Keywords:

Sarcopenia

Obesity

Lipids

Aged

80 and over

\begin{abstract}
A B S T R A C T
Aim: To analyze the lipid profile of older people aged $\geq 80$ years according to body composition (high fat mass, low muscle mass and both).

Material and method: : The sample consisted of 113 older people aged $\geq 80$ years. The assessment of body composition was made using Dual Energy X-ray Absorptiometry (DXA) and the lipid profile analysis using an enzymatic colorimetric kit. We used Analysis of Variance (ANOVA) test to compare the mean of lipid profile according to body composition and were constructed logistic regression models to verify the association between these two variables.

Results: It was found that older people with high fat had higher mean values of TG compared to normal and low muscle mass group. Older people with low muscle mass showed mean values of LDL-c lower than other groups. It was observed that older people with high fat is more likely to have (OR $2.70 ; 95 \% \mathrm{CI}$ 1.14-6.37) high blood concentration of TG.

Conclusion: Thus, it appears that high fat is related to the high blood concentration of TG in older people aged $\geq 80$ years, especially those with Asian origin and diabetes besides those with low muscle mass shows lower mean values of LDL-c.
\end{abstract}

() 2016 Diabetes India. Published by Elsevier Ltd. All rights reserved.

\section{Introduction}

In recent decades, studies investigating changes in components of body composition during the aging process and their implications on health have increased considerably. However, this issue still needs further investigation, particularly with regard to subjects aged 80 years or over [1] due to the rapidly rising population in this age group [2], and their higher risk of developing diseases related to the aging process.

High body fat is related to several chronic diseases [3-5]. One example is dyslipidemia that is usually associated with excess body fat [6] and is highly prevalent in the older people [7]. Recent studies have pointed out that in addition to high fat, low muscle

\footnotetext{
* Corresponding author at: Department of Physical Education, Universidade Estadual Paulista, Rua Roberto Simonsen 305, Presidente Prudente, São Paulo 19060-900, Brazil.

E-mail address: luisgobbo@fct.unesp.br (L.A. Gobbo).
}

mass is also a condition that predisposes people to a dyslipidemia $[8,9]$.

In subjects who present high fat and low muscle mass concomitantly $[10,11]$ metabolic complications may be higher [12], increasing the public health care cost [13]. Thus, the aim of this study was to analyze possible differences in the lipid profile of Brazilian subjects aged 80 years or over, classified with high fat, low muscle mass and both condition.

\section{Material and methods}

\subsection{Sampling}

Subjects aged 80 years or over, of both gender, residents of Presidente Prudente, HDI $=0.806$ [2], located in the west of Sao Paulo state, Brazil, were invited to participate in the present study. The invitation to participate was made by telephone to those who were attended by the public health service of the city. 
Individuals who were; bedridden; residents of rural areas; institutionalized; had a pacemaker; had difficulty walking and/or incomplete data in the database, were excluded from the present sample. A total of 113 individuals of both genders fulfilled the inclusion criteria and took part in the study.

The eligible individuals were informed about the objectives and methodology for data collection and advised they could withdraw at any time. Only those who signed the consent form were included in the sample. All protocols were reviewed and approved by the Research Ethics Committee of the University Estadual Paulista (Protocol number 26/2009).

\subsection{Lipid profile}

Blood samples were collected in a private laboratory, after $12-\mathrm{h}$ of fasting. Samples were collected in vacuum tubes containing gel with anticoagulant. After collection, blood was centrifuged for $10 \mathrm{~min}$ at $3000 \mathrm{rpm}$ to separate the serum from other blood components, allowing the use of serum for the analysis. To measure total cholesterol (TC) and its fractions (HDL-cholesterol (HDL-c) and LDL-cholesterol (LDL-C), and triglycerides (TG) an enzymatic colorimetric kit was used, processed in an Autohumalyzer A5 [14]. The reference values adopted for characterization of dyslipidemia were TG $>150 \mathrm{mg} / \mathrm{dl}$ $\mathrm{TC}>200 \mathrm{mg} / \mathrm{dl}$,

LDL-c $>130 \mathrm{mg} / \mathrm{dl}$ and HDL-c $<40 \mathrm{mg} / \mathrm{dl}$ for male and $<50 \mathrm{mg} / \mathrm{dl}$ for female [15].

\subsection{Body composition}

Body composition was estimated using Dual Energy X-ray Absorptiometry (DXA) equipment (Lunar DPX-NT; General Electric Healthcare, Little Chalfont, Buckinghamshire [software version 4.7]). The measurement lasted for approximately $15 \mathrm{~min}$ during which time the subjects remained immobile in a supine position, wearing light clothing, with their arms by their sides. The results were transmitted to a computer connected to the device and the results were recorded in grams, and analysed by a single reviewer.

For body fat, the percentage values of total fat measured were recorded, while for the muscle mass the values of two components, the lower and upper limbs from the right and left hemisphere were recorded to get appendicular skeletal muscle mass (ASM) variable. The skeletal muscle mass index (SMI) was obtained by dividing the appendicular skeletal muscle mass by the square of height $(\mathrm{kg} / \mathrm{m} 2)$.

\subsection{Definition of groups}

After assessment of the lipid profile and body composition, the individuals were divided into four groups: High fat - men and women with fat percentage greater than $27 \%$ and $38 \%$, respectively [16]; Low muscle mass - men and women with SMI lower than $7.59 \mathrm{~kg} / \mathrm{m}^{2}$ and $5.57 \mathrm{~kg} / \mathrm{m}^{2}$, respectively (the adoption of these cutoffs was based on 2 standard deviations below the mean of a

Table 1

General characteristics of the subjects according to blood concentration of total cholesterol and triglycerides.

\begin{tabular}{|c|c|c|c|c|c|c|}
\hline \multirow[t]{2}{*}{ Characteristics } & \multicolumn{2}{|l|}{$\mathrm{TC}$} & \multirow[b]{2}{*}{$\mathrm{p}$} & \multicolumn{2}{|l|}{ TG } & \multirow[b]{2}{*}{$\mathrm{p}$} \\
\hline & Normal n (\%) & High n (\%) & & Normal n (\%) & High n (\%) & \\
\hline \multicolumn{7}{|l|}{ Age (years) } \\
\hline $80-84$ & $44(50.6)$ & $43(49.4)$ & \multirow[t]{2}{*}{0.459} & $62(71.3)$ & 25 (28.7) & \multirow[t]{2}{*}{0.570} \\
\hline$\geq 85$ & $11(42.3)$ & $15(57.7)$ & & 20 (76.9) & $06(23.1)$ & \\
\hline \multicolumn{7}{|l|}{ Gender } \\
\hline Male & $29(70.7)$ & $12(29.3)$ & \multirow[t]{2}{*}{$\leq 0.001$} & $31(75.6)$ & $10(24.4)$ & \multirow[t]{2}{*}{0.584} \\
\hline Female & $26(36.1)$ & $46(63.9)$ & & $51(70.8)$ & $21(29.2)$ & \\
\hline \multicolumn{7}{|l|}{ Ethnicity } \\
\hline White & $29(46.0)$ & $34(54.0)$ & \multirow[t]{3}{*}{0.026} & $46(73.0)$ & $17(27.0)$ & \multirow[t]{3}{*}{0.057} \\
\hline Black/brown & $22(64.7)$ & $12(35.3)$ & & $28(82.4)$ & $06(17.6)$ & \\
\hline Asian & $04(25.0)$ & $12(75.0)$ & & $08(50.0)$ & $08(50.0)$ & \\
\hline \multicolumn{7}{|l|}{ Educational level } \\
\hline No education & $18(54.5)$ & $15(45.5)$ & \multirow[t]{3}{*}{0.322} & $26(78.8)$ & $07(21.2)$ & \multirow[t]{3}{*}{0.486} \\
\hline Elementary school & $30(51.7$ & $28(48.3)$ & & $43(74.1)$ & $15(25.9)$ & \\
\hline High school/higher education & $04(30.8)$ & $09(69.2)$ & & $08(61.5)$ & $05(38.5)$ & \\
\hline \multicolumn{7}{|l|}{ Marital status } \\
\hline Single/separated & $6(66.7)$ & $3(33.3)$ & \multirow[t]{3}{*}{$\leq 0.001$} & $08(88.9)$ & $01(11.1)$ & \multirow[t]{3}{*}{0.018} \\
\hline Married/has partner & $26(70.3)$ & $11(29.7)$ & & $32(86.5)$ & $05(13.5)$ & \\
\hline Widowed & $23(34.3)$ & $44(65.7)$ & & $42(62.7)$ & $25(37.3)$ & \\
\hline \multicolumn{7}{|l|}{ Smoking } \\
\hline Never & $30(41.3)$ & $41(57.7)$ & \multirow[t]{3}{*}{0.203} & $49(69.0)$ & $22(31.0)$ & \multirow[t]{3}{*}{0.448} \\
\hline Current & $5(62.5)$ & $3(37.5)$ & & $07(87.5)$ & $01(12.5)$ & \\
\hline Former & $20(58.8)$ & $14(41.2)$ & & $26(76.5)$ & $08(23.5)$ & \\
\hline \multicolumn{7}{|l|}{ BMI $\left(\mathrm{Kg} / \mathrm{m}^{2}\right)$} \\
\hline Eutrophic & $19(39.6)$ & $29(60.4)$ & \multirow[t]{3}{*}{0.247} & $34(70.8)$ & $14(29.2)$ & \multirow[t]{3}{*}{0.024} \\
\hline Underweigth & $17(56.7)$ & $13(43.3)$ & & $27(90.0)$ & $03(10.0)$ & \\
\hline Obese & $19(54.3)$ & $16(45.7)$ & & $21(60.0)$ & $14(40.0)$ & \\
\hline \multicolumn{7}{|l|}{ Waist $(\mathrm{cm})$} \\
\hline Normal & $31(48.4)$ & $33(51.6)$ & 0.954 & $54(84.4)$ & $10(15.6)$ & $\leq 0.001$ \\
\hline High & $24(49.0)$ & $25(51.0)$ & & $28(57.1)$ & $21(42.9)$ & \\
\hline Diabetes & & & & & & \\
\hline No & $43(46.2)$ & $50(53.8)$ & 0.177 & $72(76.6)$ & $22(23.4)$ & 0.033 \\
\hline Yes & $12(63.2)$ & $07(36.8)$ & & $10(52.6)$ & $09(47.4)$ & \\
\hline Hypothyroidism & & & & & & \\
\hline No & $53(50.0)$ & $53(50.0)$ & 0.427 & $78(72.9)$ & $29(27.1)$ & 0.739 \\
\hline Yes & $02(33.3)$ & $04(66.7)$ & & $04(66.7)$ & $02(33.3)$ & \\
\hline
\end{tabular}


group of Brazilian young people aged between 20 and 30 years, as suggested by Baumgartner et al. [17]; High fat + low muscle mass - subjects who presented the two conditions concomitantly; Normal - those without high fat or low muscle mass.

\subsection{Demographic and socioeconomic variables}

The information referring to variables: age, gender, ethnicity, educational level, marital status e smoking were raised through interviews.

\subsection{Anthropometric measurements}

Body weight was measured by an electronic scale and height was measured by a fixed stadiometer. These measurements were used for calculating BMI [weight $(\mathrm{kg}) /$ height $\left.(\mathrm{m})^{2}\right]$, and were performed following the procedures described by Freitas Júnior et al. [18].

The classification of BMI of older people was performed according to the values suggested by Troiano et al. [19].

Waist circumference was measured in millimeters at the midpoint between the iliac crest and last rib with an anthropometric metal tape. The cut-off values adopted for the indication of abdominal obesity were $88 \mathrm{~cm}$ for women and $102 \mathrm{~cm}$ for men [20].

\subsection{Diseases - diabetes and hypothyroidism}

To determine the prevalence of diabetes e hypothyroidism was utilized a summarized self-reported questionnaire of morbidities from the Standard Health Questionnaire for Washington State, consisting of a closed investigation, and analysed the presence/ absence of chronic diseases, divided into three groups: metabolic, cardiovascular and osteoarticular. The main investigated diseases are hypertension, diabetes, dyslipidemia, disorders in the thyroid, osteoporosis, osteoarthritis and diseases in spine [21].

\subsection{Statistical analysis}

The chi-square test was used with a descriptive analysis of the sample and to analyze the relationship of lipid profile between the groups (normal, high fat, low fat-free mass and both condition). We utilized Analysis of Variance (ANOVA) test to compare the mean of lipid profile according to body composition. The post-hoc multiple comparisons Tuked test was used to verify which of these four groups were significantly different from each other and Students' $t$-test for independent samples were used for the comparison of variables between normal and others groups. Finally, we constructed univariate and multivariate logistic regression models to express the magnitude of the associations in Odds Ratios (OR) and respective $95 \%$ Confidence Intervals $(95 \% \mathrm{CI})$. All analyses were performed using SPSS software (SPSS inc. Chicago. IL), version 17.0, and the significance level was set at $5 \%$.

\section{Results}

The sample consisted of 113 older people aged between 80 and 95 years $(83.4 \pm 2.9$ years $)$, of which 72 women ( $83.5 \pm 3.1$ years) and 41 men $(83.3 \pm 2.6$ years $)$.

We analysed the prevalence of dyslipidemia in older people within each group investigated and was observed that the obese group showed a higher percentage $(52.1 \%)$ of older people with

Table 2

General characteristics of the subjects according to blood concentration of LDL-c and HDL-c.

\begin{tabular}{|c|c|c|c|c|c|c|}
\hline \multirow[t]{2}{*}{ Characteristics } & \multicolumn{2}{|l|}{ LDL-C } & \multirow[b]{2}{*}{$\mathrm{p}$} & \multicolumn{2}{|l|}{ HDL-C } & \multirow[b]{2}{*}{$\mathrm{p}$} \\
\hline & Normal n (\%) & High n (\%) & & Normal n (\%) & Low n (\%) & \\
\hline \multicolumn{7}{|l|}{ Age (anos) } \\
\hline $80-84$ & $52(59.8)$ & $35(40.2)$ & \multirow[t]{2}{*}{0.219} & $61(70.1)$ & $26(29.9)$ & \multirow[t]{2}{*}{0.771} \\
\hline$\geq 85$ & $12(46.2)$ & $14(53.8)$ & & $19(73.1)$ & 07 (26.9) & \\
\hline \multicolumn{7}{|l|}{ Gender } \\
\hline Male & $31(75.6)$ & $10(24.4)$ & \multirow[t]{2}{*}{0.002} & $33(80.5)$ & $08(19.5)$ & \multirow[t]{2}{*}{0.087} \\
\hline Female & $33(45.8)$ & $39(54.2)$ & & $47(65.3)$ & $25(34.7)$ & \\
\hline \multicolumn{7}{|l|}{ Ethnicity } \\
\hline White & $35(55.6)$ & $28(44.4)$ & \multirow{3}{*}{0.129} & $43(68.3)$ & $20(31.7)$ & \multirow{3}{*}{0.684} \\
\hline Black/brown & $23(67.6)$ & $11(32.4)$ & & $26(76.5)$ & $08(23.5)$ & \\
\hline Asian & $06(37.5)$ & $10(62.5)$ & & $11(68.3)$ & $05(31.3)$ & \\
\hline \multicolumn{7}{|l|}{ Educational level } \\
\hline No education & $20(60.6)$ & $13(39.4)$ & \multirow[t]{3}{*}{0.284} & $22(66.7)$ & $11(33.3)$ & \multirow[t]{3}{*}{0.579} \\
\hline Elementary school & $36(62.1)$ & $22(37.9)$ & & $43(74.1)$ & 15 (25.9) & \\
\hline High school/higher education & $05(38.5)$ & $08(61.5)$ & & $08(61.5)$ & $05(38.5)$ & \\
\hline \multicolumn{7}{|l|}{ Marital status } \\
\hline Single/separated & $06(66.7)$ & $03(33.3)$ & \multirow[t]{3}{*}{0.008} & $07(77.8)$ & $02(22.2)$ & \multirow[t]{3}{*}{0.587} \\
\hline Married/has partner & $28(75.7)$ & $09(24.3)$ & & $28(75.7)$ & $09(24.3)$ & \\
\hline Widowed & $30(44.8)$ & $37(55.2)$ & & $45(67.2)$ & $22(32.8)$ & \\
\hline \multicolumn{7}{|l|}{ Smoking } \\
\hline Never & $36(50.7)$ & $35(49.3)$ & \multirow[t]{3}{*}{0.246} & $48(67.6)$ & $23(32.4)$ & \multirow[t]{3}{*}{0.623} \\
\hline Current & $05(62.5)$ & $03(37.5)$ & & $06(75.0)$ & $02(25.0)$ & \\
\hline Former & $23(67.6)$ & $11(32.4)$ & & $26(76.5)$ & $08(23.5)$ & \\
\hline \multicolumn{7}{|l|}{$\mathrm{BMI}\left(\mathrm{Kg} / \mathrm{m}^{2}\right)$} \\
\hline Eutrophic & $21(43.8)$ & $27(56.3)$ & \multirow[t]{3}{*}{0.059} & $33(68.6)$ & $15(31.3)$ & \multirow[t]{3}{*}{0.057} \\
\hline Underweigth & $20(66.7)$ & $10(33.3)$ & & $26(86.7)$ & $04(13.3)$ & \\
\hline Obese & $23(65.7)$ & $12(34.3)$ & & $21(60.0)$ & $14(40.0)$ & \\
\hline \multicolumn{7}{|l|}{ Waist (cm) } \\
\hline Normal & $35(54.7)$ & $29(45.3)$ & 0.633 & $48(75.0)$ & $16(25.0)$ & 0.261 \\
\hline High & $29(59.2)$ & $20(40.8)$ & & $32(65.3)$ & $17(34.7)$ & \\
\hline Diabetes & & & & & & \\
\hline No & $51(54.3)$ & $43(45.7)$ & 0.256 & $70(74.5)$ & $24(25.5)$ & 0.056 \\
\hline Yes & $13(68.4)$ & $06(31.6)$ & & $10(52.6)$ & $09(47.4)$ & \\
\hline Hypothyroidism & & & & & & \\
\hline No & $62(57.9)$ & $45(42.1)$ & 0.237 & $76(71.0)$ & $31(29.0)$ & 0.819 \\
\hline Yes & $02(33.3)$ & $04(66.7)$ & & $04(66.7)$ & $02(33.3)$ & \\
\hline
\end{tabular}


dyslipidemia compared to the normal (26.0\%), low muscle mass (5.5\%) and high mass + low muscle mass (16.4\%) groups, however, these values were not statistically significant $(\mathrm{p}=0.170)$.

Table 1 shows general characteristics of the subjects according to blood concentration of total cholesterol and triglycerides. It was observed that women, widowed and Asian ethnicity, showed higher blood concentration of TC above recommended. On the other hand, older people with obesity, high WC, widowed and diabetics had higher concentrations of TG above recommended.

Regarding blood concentration of LDL-c and HDL-c, it was observed that women and widowed had higher blood concentration of LDL-c above recommended. There was no difference between the descriptive variables for concentration of HDL-c (Table 2).

Table 3 shows a comparison between body composition and lipid profile. It was found that older people with high fat had higher mean values of TG compared to the normal group and low muscle mass. Older people with low muscle mass showed mean value of LDL-c lower the other groups and older people with high fat plus low muscle mass showed mean value of HDL-c lower compared to the normal group. However, in none of the groups observed mean values above (TG, TC, LDL-C) or below (HDL-C) of recommended.

It was observed that high body fat is related to the blood concentration of TG (Table 4), and older people with high body fat are more likely to have high blood concentration of TG. In association analysis between high body fat and blood concentration of TG adjusted, it was found that high body fat is associated with high blood concentration of TG independent of marital status. In model 3 it was found that the variable ethnicity showed statistically significant, with OR 5.08 values (95\% CI 1.39 to 18.52 ), indicating a greater chance of risk for older people with Asian origin. In model 4 variables ethnicity and diabetes showed statistical significance, with OR 5.35 (95\% CI 1.40 to 20.45) and OR 3.48 (1.12 to 10.86 ), respectively (Table 5 ).

\section{Discussion}

The present study aimed to analyze the lipid profile and the possible differences between groups (normal, high fat, low muscle mass, and both condition) in Brazilians aged 80 years or over; it was observed that high fat is related to the high blood concentration of TG. Furthermore older people with low muscle mass showed mean value of LDL-c lower the other groups.

Older people with obesity showed higher prevalence of dyslipidemia in this study. Indeed high body fat is associated with the prevalence of cardiometabolic diseases, including dyslipidemia [22,23]. Such evidence can be attributed to the production of proinflammatory cytokines by adipose tissue, such as the tumor necrosis factor (TNF- $\alpha$ ) and interleukin 6 (IL-6), that are released into the bloodstream and through different mechanisms generate processes related to decreased uptake of glucose by target tissues and therefore increased use of free fatty acids in the bloodstream [24].

Because the biological characteristics, the women have a greater amount of body fat [22,25] and, consequently, have a higher prevalence of dyslipidemia compared to men [22,23]. Our findings corroborate to the studies above mentioned. The higher prevalence of dyslipidemia in widowed observed in this study may have occurred due to the composition of our sample, with the highest percentage of women, who in most cases are widows $79 \%$ $(\mathrm{p} \leq 0.001)$.

It was observed high prevalence of dyslipidemia in older people with Asian origin. Similar result was previously found by Lerario et al. [26] with Brazilian older people descendants of Asian in which was observed high prevalence of dyslipidemia in this population mediated by excess abdominal fat. In subjects with diabetes, insulin resistance as well as reduction in the activity of lipoprotein lipase in the muscle and adipocytes contribute with the prevalence of dyslipidemia, mainly of hypertriglyceridemia [27].

Table 3

Comparison between body composition and lipid profile of the Brazilian older people aged 80 years or over.

\begin{tabular}{|c|c|c|c|c|}
\hline & $\begin{array}{l}\text { Normal } \\
(\mathrm{n}=28) \\
\text { Mean }(\mathrm{SD})\end{array}$ & $\begin{array}{l}\text { High fat } \\
(n=53) \\
\text { Mean }(S D)\end{array}$ & $\begin{array}{l}\text { Low muscle mass } \\
(\mathrm{n}=11) \\
\text { Mean (SD) }\end{array}$ & $\begin{array}{l}\text { High fat }+ \text { Low muscle mass } \\
(n=21) \\
\text { Mean }(S D)\end{array}$ \\
\hline $\mathrm{TG}(\mathrm{mg} / \mathrm{dl})$ & $116.2(68.2)^{* a}$ & $149.0(65.0)^{*} \mathrm{~b}$ & $105.8(65.3)^{\mathrm{a}}$ & $123.8(35.1)^{\mathrm{ab}}$ \\
\hline $\mathrm{TC}(\mathrm{mg} / \mathrm{dl})$ & $204.3(45.0)$ & $205.0(38.0)$ & $177.4(43.3)$ & $196.7(37.4)$ \\
\hline LDL- c (mg/dl) & $129.0(42.4)^{*} \mathrm{a}$ & $123.2(31.0)^{\mathrm{a}}$ & $90.4(43.6)^{*} b$ & $125.8(32.8)^{a}$ \\
\hline HDL- c (mg/dl) & $52.0(12.9)^{*}$ & $52.0(11.7)$ & $56.3(11.9)$ & $46.2(6.6)^{*}$ \\
\hline
\end{tabular}

Note: TG = triglycerides; TC= total cholesterol; $\mathrm{LDL}=$ low-density lipoprotein cholesterol; HDL = high-density lipoprotein cholesterol; SD = standard deviation.

Letters difference mean difference between groups, comparison between four groups.

$\mathrm{p} \leq 0,05$.

difference normal group, comparison only between normal group.

Table 4

Relationship between body composition and lipid profile of the Brazilian older people aged 80 years or over.

\begin{tabular}{|c|c|c|c|c|c|c|c|c|}
\hline \multirow[t]{2}{*}{ Body composition } & \multicolumn{2}{|l|}{$\mathrm{TC}$} & \multicolumn{2}{|l|}{ TG } & \multicolumn{2}{|l|}{ LDL-c } & \multicolumn{2}{|l|}{ HDL-c } \\
\hline & Normal n (\%) & High n (\%) & Normal n (\%) & High n (\%) & Normal n (\%) & High n (\%) & Normal n (\%) & Low n (\%) \\
\hline \multicolumn{9}{|l|}{ High fat (\%) } \\
\hline No & $30(50.0)$ & $30(50.0)$ & $49(81.7)$ & $11(18.3)$ & $33(55.0)$ & $27(45.0)$ & $45(75.0)$ & $15(25.0)$ \\
\hline Yes & $25(47.2)$ & $28(52.8)$ & $33(62.3)$ & $20(37.7)$ & $31(58.5)$ & $22(41.5)$ & $35(66.0)$ & $18(34.0)$ \\
\hline p-value & 0.764 & & 0.021 & & 0.709 & & 0.296 & \\
\hline \multicolumn{9}{|c|}{ Low muscle mass $\left(\mathrm{Kg} / \mathrm{m}^{2}\right)$} \\
\hline No & $47(46.1)$ & $55(53.9)$ & $72(70.6)$ & $30(29.4)$ & $56(54.9)$ & $46(45.1)$ & $70(68.6)$ & $32(31.4)$ \\
\hline Yes & $08(72.7)$ & $03(27.3)$ & $10(90.9)$ & $01(9.1)$ & $08(72.7)$ & $03(27.3)$ & $10(90.9)$ & $01(9.1)$ \\
\hline p-value & 0.093 & & 0.151 & & 0.257 & & 0.123 & \\
\hline \multicolumn{9}{|c|}{ High fat $(\%)+$ Low muscle mass $\left(\mathrm{Kg} / \mathrm{m}^{2}\right)$} \\
\hline No & $45(48.9)$ & $47(51.1)$ & $66(71.7)$ & $26(28.3)$ & $52(56.5)$ & $40(43.5)$ & $66(71.7)$ & $26(28.3)$ \\
\hline Yes & $10(47.6)$ & $11(52.4)$ & $16(76.2)$ & $05(23.8)$ & $12(57.1)$ & 09 (42.9) & $14(66.7)$ & $07(33.3)$ \\
\hline p-value & 0.915 & & 0.680 & & 0.959 & & 0.645 & \\
\hline
\end{tabular}


Tabela 5

Univariate and multivariate logistic regression models of the relationship between high fat and triglycerides in Brazilian older people aged 80 years or over.

\begin{tabular}{|c|c|c|c|c|c|c|c|c|}
\hline & \multicolumn{2}{|c|}{ Model 1} & \multicolumn{2}{|c|}{ Model 2} & \multicolumn{2}{|c|}{ Model 3} & \multicolumn{2}{|c|}{ Model 4} \\
\hline & OR & CI 95\% & OR & CI 95\% & OR & CI 95\% & OR & CI 95\% \\
\hline High Fat (\%) & 2.70 & $1.14-6.37$ & 3.43 & $1.36-8.64$ & 4.41 & $1.60-12.17$ & 4.70 & $1.65-13.38$ \\
\hline
\end{tabular}

Model 1 = unadjusted.

Model $2=$ model 1 plus marital status.

Model $3=$ model 1 plus ethnicity.

Model $4=$ model 3 plus diabetes.

Such evidence may also be found in our study, since approximately $47 \%$ of subjects with diabetes had hypertriglyceridemia.

Studies have shown an increase of $23 \%$ in the risk of developing cardiovascular disease in the older people with high fat and low muscle mass concomitantly $[12,28]$. However, in a study by Messier et al. [8] with menopausal women, no differences were found between the lipid profile of women with high body fat plus low muscle mass. On the other hand the authors AubertinLeheudre et al. [29] also investigated menopausal women, with a mean age of 66 years, and they found that women with high body fat alone had a worse lipid profile compared to those with high fat plus low muscle mass. These results are similar to those found in our study.

One of the main types of dyslipidemia associated with high body fat is hypertriglyceridemia [23,25]. In a study with Koreans older people [28], no statistically significant differences were observed in the TG variable between the four groups analysed, although the high fat group presented a higher mean value compared to the other groups. Aubertin-Leheudre et al. [29] also observed higher blood concentrations of TG in women with high body fat. This result is similar to the present study, in which there was a direct relationship between high fat and high TG with a greater chance of risk for hypertriglyceridemia in older people with high body fat.

With regard to the blood concentrations of TC and the presence of low muscle mass, in a study by Sanada et al. [30] a comparison was made between adult males with low muscle mass and a group without the presence of this condition and no statistical difference was observed in the serum concentration of TC. However, the value of this variable was lower for those with low muscle mass. This result is similar to the findings of the present investigation, where it was observed that the older people with low muscle mass showed lower values of TC compared to the other groups, however, without statistically significant differences being observed.

The low muscle mass group also had significantly lower blood concentration of LDL than the other groups. One possible explanation for these results is that muscle mass is related to fat oxidation and resting energy expenditure, so decrease in muscle mass may contribute to the reduction of energy expenditure and, consequently, increasing the concentration of lipids in the blood [31,32]. However, the reduction of food intake, especially animal protein, which occurs with aging due to factors such as impaired oral health, may explain the low concentration of LDL-c in the older people with low muscle mass [30]. In addition, older people with low muscle mass lose more type II fibers (fast twitch) than type I (slow twitch), indicating that the reduction of muscle mass doesn't necessarily imply an dyslipidemia, other factors such as the characteristics of the muscle (fiber composition) may also be related [8].

Despite researching a subject which still needs to be further explored in the literature, and especially, in the population aged 80 years or over in developing countries such as Brazil, the present study has some limitations that should be mentioned. One of them is the cross-sectional design which limits the ability to establish causality relationships and thus it is suggested that future studies should conduct prospective trials involving this subject and this age group.

\section{Conclusion}

Thus, it appears that high fat is related to the high blood concentration of TG in older people aged 80 years or over, especially those with Asian origin and diabetes and those with low muscle mass showed lower mean values of LDL-c. Public policy focusing on primary prevention of dyslipidemia should be conducted on this specific population and the younger people, in order to improve the quality of life of these individuals during the aging process.

\section{Conflicts of interest}

None to declare.

\section{Funding sources}

None.

\section{Acknowledgments}

We would like to thank the Conselho Nacional de Desenvolvimento Científico e Tecnológico, Brazil that supported by a scholarship (VRS).

\section{References}

[1] Buffa R, Floris GU, Putzu PF, Marini E. Body Composition variations in ageing. Coll Antropol 2011;35(1):259-65.

[2] IBGE -Instituto Brasileiro de Geografia e Estatística. Censo Demográfico e Contagem da População: População residente por sexo, situação e grupos de idade. Available from: www.sidra.ibge.gov.br.

[3] Haslam D. Understanding obesity in the older person: prevalence and risk factors. Br J Community Nurs 2008;13(3):115-6.

[4] Prado CM, Wells JC, Smith SR, Stephan BC, Siervo M. Sarcopenic obesity: a Critical appraisal of the current evidence. Clin Nutr 2012;31(5):583-601.

[5] Chung JY, Kang HT, Lee DC, Lee HR, Lee YJ. Body composition and its association with cardiometabolic risk factors in the elderly: a focus on sarcopenic obesity. Arch Gerontol Geriatr 2013;56(1):270-8.

[6] Palacios C, Pérez CM, Guzmán M, Ortiz AP, Ayala A, Suárez E. Association between adiposity indices and cardiometabolic risk factors among adults living in Puerto Rico. Public Health Nutr 2011;14(10):1714-23.

[7] Putaala J, Yesilot N, Waje-Andreassen U, Pitkaniemi J, Vassilopoulou S, Nardi K, et al. Demographic and geographic vascular risk factor differences in European young adults with ischemic stroke: the 15 cities young stroke study. Stroke 2012;43(10):2624-30.

[8] Messier V, Karelis AD, Lavoie ME, Brochu M, Faraj M, Strychar I, et al. Metabolic profile and quality of life in class I sarcopenic overweight and obese postmenopausal women: a MONET study. Appl Physiol Nutr Metab 2009;34 (1):18-24.

[9] Hwang B, Lim JY, Lee J, Choi Nam-Kyong, Ahn Yoon-Ok, Park Byung-Joo. Prevalence rate and associated factors of sarcopenic obesity in Korean elderly population. J Korean Med Sci 2012;27(7):748-55.

[10] Zamboni M, Mazzali G, Fantin F, Rossi A, Di Francesco V. Sarcopenic obesity: a new category of obesity in the elderly. Nutr Metab Cardiovasc Dis 2008;18 (5):388-95.

[11] Oliveira RJ, Bottaro M, Júnior JT, Farinatti PT, Bezerra LA, Lima RM. Identification of sarcopenic obesity in postmenopausal women: a cutoff proposal. Braz J Med Biol Res 2011;44(11):1171-6.

[12] Stephen WC, Janssen I. Sarcopenic-obesity and cardiovascular disease risk in the elderly. J Nutr Health Aging 2009;13(5):460-6.

[13] Li Z, Heber D. Sarcopenic obesity in the elderly and strategies for weight management. Nutr Rev 2012;70(1):57-64.

[14] Human RP, Jones GA. Evaluation of swab transport systems against a published standard. J Clin Pathol 2004;57(7):762-3. 
[15] Brazilian Society of Cardiology. IV brazilian guidelines on dyslipidemia and prevention of atherosclerosis. department of atherosclerosis of the brazilian society of cardiology. Arq Bras Cardiol 2007;88(Suppl. 1):2-19.

[16] Baumgartner RN. Body composition in healthy aging. Ann N Y Acad Sci 2000;904:437-48.

[17] Baumgartner RN, Koehler KM, Gallagher D, Romero L, Heymsfield SB, Ross RR, et al. Epidemiology of sarcopenia among the elderly in New Mexico. Am J Epidemiol 1998;147(8):755-63.

[18] Freitas Junior IF, Bueno DR, Buonani C, Codogno JS, Conterato I, Fernandes RA, et al. Padronização de Técnicas Antropométricas. Presidente Prudente, SP: Cultura Acadêmica. .

[19] Troiano RP, Frongillo EAJR, Sobal J, Levitsky DA. The relationship between body weight and mortality: a quantitative analysis of combined information from existing studies. Int J Obes Relat Metab Disord 1996;20(1):63-75.

[20] Lean ME, Han TS, Seidell JC. Impairment of health and quality of life in people with large waist circumference. Lancet 1998;351(9106):853-6.

[21] Washington State Health Insurance Pool. Standard Health Questionnaire for Washington State. Washington.

[22] Fernandes RA, Christofaro DGD, Casonatto J, Codogno JS, Rodrigues EQ, Cardoso ML, et al. Prevalence of dyslipidemia in individuals physically active during childhood, adolescence and adult age. Arq Bras Cardiol 2011;97(4):31723.

[23] Garcez MR, Pereira JL, Fontanelli MM, Marchioni DML, Fisberg RM. Prevalence of dyslipidemia according to the nutritional status in a representative sample of São Paulo. Arq Bras Cardiol 2014;103(6):476-84.
[24] Diaz MN, Frei B, Vita JA, Keaney Jr. JF. Antioxidants and atherosclerotic heart disease. N Engl J Med 1997;337:408-16.

[25] Gomes IC, Santos VR, Christofaro DGD, Santos LL, Freitas Júnior IF. The most frequent cardiovascular risk factors in Brazilian aged 80 years or older. J Appl Gerontol 2013;32(4):408-21.

[26] Lerario DDG, Gimeno SG, Franco LJ, Lunes M, Ferreira SRG. Weight excess and abdominal fat in the metabolic syndrome among Japanese-Brazilians. Rev Saúde Pública 2002;36(1):4-11.

[27] Jaiswal M, Schinske A, Pop-Busui R. Lipids and lipid management in diabetes. Best Pract Res Clin Endocrinol Metab 2014;28(3):325-38.

[28] Lim S, Kim JH, Yoon JW, Kang SM, Choi SH, Park YJ, et al. Sarcopenic obesity: prevalence and association with metabolic syndrome in the Korean Longitudinal Study on Health and Aging (KLoSHA). Diabetes Care 2010;33 (7):1652-4.

[29] Aubertin-Leheudre M, Lord C, Goulet ED, Khalil A, Dionne IJ. Effect of sarcopenia on cardiovascular disease risk factors in obese postmenopausal women. Obesity 2006;14(12):2277-83.

[30] Sanada K, Miyachi M, Tanimoto M, Yamamoto K, Murakami H, Okumura S, et al . A cross-sectional study of sarcopenia in Japanese men and women: reference values and association with cardiovascular risk factors. Eur J Appl Physiol 2010;110(1):57-65.

[31] Deschenes MR. Effects of aging on muscle fibre type and size. Sports Med 2004;34(12):809-24.

[32] Trevisan MC, Burini RC. Resting metabolism of post-menopause women submitted to a training program with weights (hypertrophy). Rev Bras Med Esporte 2007;13(2):133-7. 